\title{
Inhalation sedation with the 'Anaesthetic Conserving Device' for patients in intensive care units: A literature review
}

BY KARNJUŠ I, MEKIŠ D, KRIŽMARIĆ M

\section{Abstract}

Background. The Anaesthetic Conserving Device is a modified heat and moisture exchanger that enables the application of inhalation sedation with existing ventilators in intensive care units. The following review describes the advantages of inhalation sedation using the Anaesthetic Conserving Device in comparison to standard intravenous sedation for patients in intensive care units and highlights the technical aspects of its functioning.

Methods. The literature search was limited to PubMed, Sage Journals and CINAHL databases, using the terms "anaesthetic conserving device«, »volatile anaesthetic reflection filter «, »AnaConDa « independently and in connection with the terms »sedation « and $»$ intensive care unit «. Included are articles published up until December 2014. 
Results. Use of inhalation sedation with the Anaesthetic Conserving Device enables faster transition to spontaneous breathing and a shorter awakening time than with intravenous sedation. Even short-term inhalation sedation of patients after open heart procedures has a cardioprotective effect and reduces troponin $T$ values. Despite increased concentrations of inorganic fluoride in serum after sevoflurane exposure, no clinical studies to date have shown its nephrotoxic effect, even after long-term ( $48 \mathrm{~h}$ ) sedation. The Anaesthetic Conserving Device is accurate in maintaining target values of volatile anaesthetics. However, increased dead space volume was found in several studies, exceeding the internal volume of the Anaesthetic Conserving Device.

Conclusion. Results to date show that inhalation sedation with the Anaesthetic Conserving Device may be an effective and safe alternative to existing protocols of intravenous sedation for patients requiring intensive treatment.

Key words: anaesthetic conserving device, inhalational sedation, intravenous sedation, intensive care unit

\section{Introduction}

Effective sedation and analgesia are indispensable elements of treating patients in intensive care units (ICU) in order to reduce pain, anxiety, and agitation during mechanical ventilation and when other invasive diagnostic and therapeutic interventions are performed. $(1,2)$ Current guidelines for analgesia and sedation of patients in ICU favour the use of intravenous forms of sedation. (3) Propofol and midazolam are the most often used drugs for sedation of critically ill patients; however, the literature highlights numerous adverse effects of such intravenous anaesthetics. $(4,5)$

Compared to most intravenous anaesthetics, volatile anaesthetics, such as sevoflurane and isoflurane, offer better control of sedation since they do not accumulate or develop tolerance. Emergence times of patients sedated by inhalation are therefore shorter and more predictable than 
after intravenous sedation. (6) The end-tidal tension of a volatile anaesthetic accurately reflects arterial partial pressure, providing a precise indicator of the volatile anaesthetics partial pressure and concentration in the central nervous system. (7) Volatile anaesthetics act primarily on the cerebral cortex, depressing the consciousness and have analgesic properties even at low concentrations, while leaving many autonomic functions such as temperature control, blood pressure regulation or respiration undisturbed. (8) In comparison with intravenous anaesthetics, they are mainly excreted via the respiratory system, so only a minor part is metabolised by the liver or kidney. (6) In humans, the metabolism degrades approximately $0.2 \%$ of isoflurane and 2-5\% of sevoflurane. (9) They have a bronchodilatory effect (10) and protective properties on numerous organs (above all cardioprotective and cerebroprotective). $(11,12)$

Initial attempts at conserving anaesthetic vapours using an open system involved the development of a reflector that incorporated zeolite crystals. (13) However, because of the possibility of zeolite inhalation causing pulmonary toxicity (14), one proposed solution was to use a charcoal filter instead of a zeolite one. (15) The principle of the charcoal filter was further developed, leading to the creation of a device for inhalation sedation AnaConDa ${ }^{\mathrm{TM}}$ (Anaesthetic Conserving Device; Sedana Medical, Uppsala, Sweden), which enables sedation and analgesia of patients in ICU with isoflurane and sevoflurane. (16)

The Anaesthetic Conserving Device (ACD, AnaConDa ${ }^{\mathrm{TM}}$ ) is a modified heat and moisture exchanger, which is inserted between the Y-piece of the breathing circuit and the endotracheal tube (ET-tube) (figure 1) and can be used with any type of ICU ventilator $(17,18)$ without a heated humidifier. The ACD contains active lipophilic carbon fibres, which have the capacity to bind $90 \%$ of the expired volatile anaesthetic. These are again released with the following inspiratory cycle. Leakage of the anaesthetic into the environment is thus limited and use of the volatile anaesthetic is also more economical and safer for medical personnel. The lost amount of volatile anaesthetic (10\%) is replaced by liquid 
anaesthetic, which is uninterruptedly supplied to the equipment by a standard syringe pump and then through a miniature evaporator rod vaporises into the breathing gas with which the patient is ventilated. $(8,19)$ A sampling port located on the patient side of the device allows the expired gas concentration to be continuously displayed on the gas monitor (figure 2). (20) Expired gas should be actively or passively scavenged at the gas outlet of the ventilator. (16) Enlund et al. (17) first described its clinical use for anaesthesia, and Sackey et al. (21) reported its safe use for inhalational sedation in ICU patients.

The following review describes the advantages of inhalation sedation using the $\mathrm{ACD}$ in comparison to standard intravenous sedation for patients in ICU and highlights the technical aspects of the functioning of the ACD.

\section{Methods}

A literature search was conducted using the electronic databases of PubMed, Sage Journals and the Cumulative Index to Nursing \& Allied Health Literature (CINAHL) using the following terms: "anaesthetic conserving device", "volatile anaesthetic reflection filter", "AnaConDa"; independently and in connection with terms "sedation" and "intensive care unit". The extract of hits was limited in the databases by the requirements: scientific journals, peer-reviewed articles and entire text. Works that presented protocols of research, letters to the editor and works that dealt with the use of the ACD in the operating room were not included. Thirty-seven articles were found corresponding to the aforementioned criteria and 29 were retained. We additionally excluded four review papers. Twenty-five articles that met the criteria were included in our review. Articles selected for this review were published in English before December 31, 2014.

\section{Results}

Twenty-five articles were included in our review, nine of which are 
randomised clinical studies (table 1), twelve are prospective observational studies, two case reports and two studies were performed in a laboratory environment (bench study). Most research into the ACD has been done in Sweden (8), France (6) and Germany (5). The number of patients in clinical studies varied from six to 126 patients.

\section{Inhalation sedation with the ACD in ICU - Clinical trials}

The majority of clinical studies evaluated the feasibility of inhalation sedation with the ACD and ascertained its advantages over intravenous forms of sedation. They primarily compared the awakening time of patients after sedation, which was assessed as the time from ending sedation to removal of the ET-tube and the time to an appropriate verbal response of the patient. The quality of sedation and awakening was evaluated by assessment of the depth of sedation, stability of the cardiovascular system of patients, the occurrence of delusions and hallucinations, the occurrence of adverse effects, the length of stay in the ICU and in hospital and an assessment of the costs of sedation and analgesia in the ICU. Table 1 presents the main findings of randomised clinical studies that were included in the literature review. The majority of the studies showed that the awakening time of patients sedated with volatile anaesthetic using the ACD was shorter than with intravenous sedation. (21-25) Patients sedated with volatile anaesthetics needed a shorter period of mechanical ventilation, the ET-tube was removed more quickly and cognitive functions normalised faster, irrespective of the length of sedation.

Sackey et al. (21) analysed the influence of prolonged sedation ( $>12 \mathrm{hrs}$ ) on the awakening time of sedated patients. They compared sedation with isoflurane with sedation with midazolam in a heterogeneous group of patients in ICU. The removal of the ET-tube was faster in patients sedated with volatile anaesthetic (isoflurane: $10 \pm 5 \mathrm{~min}$ ) than in patients on intravenous sedation (midazolam: $252 \pm 271 \mathrm{~min}$ ); patients after isoflurane followed simple verbal instructions faster $(10 \pm 5 \mathrm{~min})$ than patients after midazolam (110 $\pm 132 \mathrm{~min})$. Sevoflurane, because of its 
pharmacokinetic properties, provides faster induction and recovery in comparison with isoflurane. Mesnil et al. (22) analysed patients who required sedation $>24 \mathrm{hrs}$ and compared inhalation sedation with sevoflurane ( $n=19)$ with intravenous sedation with propofol $(n=14)$ or midazolam $(n=14)$. In addition to faster removal of the ET-tube and a shorter awakening time of patients sedated with volatile anaesthetic (sevoflurane: $33.6 \pm 13.1$ and $18.6 \pm 11.8 \mathrm{~min}$ ) in comparison with the other two groups on intravenous sedation (propofol: $326.11 \pm 360.2$ and $91.3 \pm 35.2 \mathrm{~min}$; midazolam: $599.6 \pm 586.6$ and $260.2 \pm 150.2 \mathrm{~min}$ ), the authors also found a better quality of awakening. Patients were less agitated and had fewer hallucinations. Studies that dealt with short-term sedation $(<12 \mathrm{hrs})$ showed similar findings. $(23,24)$

It is difficult to achieve a suitable depth of sedation with some patients in ICU using standard protocols of intravenous sedation, so higher doses of drugs or their combination are required. This can lead to over-deep sedation of patients and/or haemodynamic instability. L'her et al. (26) found that in the case of patients that needed higher doses of midazolam than the average ( $>0.05 \mathrm{mg} / \mathrm{kg} / \mathrm{h}$ ) in the first $24 \mathrm{hrs}$, an appropriate depth of sedation was achieved faster under inhalational sedation with isoflurane. The same authors also showed a lower use of analgesics (sufentanil) in the case of inhalation sedation. A similar opioid sparing effect of isoflurane was demonstrated in the study by Sackey et al. (21) Mesnil et al. (22) found that the use of opioid analgesics in the period of $24 \mathrm{hrs}$ after removal of the ET-tube was lower in the group of patients on inhalation sedation with sevoflurane than in the group that was on intravenous sedation with propofol or midazolam. Furthermore, the last recorded pain scores were significantly lower in the group on inhalation sedation.

The occurrence of adverse effects, such as arrhythmia, diarrhoea, nausea, vomiting and insufficient respiratory function in patients on inhalation sedation using the ACD has also been investigated and compared with intravenous forms of sedation. $(21,22,24)$ Significant differences in the occurrence of the aforementioned adverse effects between the two forms of sedation were not established. Studies similarly did not demonstrate 
statistically significant differences between intravenous and inhalation forms of sedation in the functioning of the circulatory system, liver and kidneys. $(23,24,26,27)$

Some concerns still remain about the nephrotoxicity of volatile anaesthetics because of the formation of fluoride ions. $(21,25)$ Three studies $(22,25,28)$ ascertained the values of inorganic fluoride in serum with patients sedated with sevoflurane. Despite increased concentrations of inorganic fluoride in serum after sevoflurane exposure, glomerular and tubular renal integrity were preserved in the patients throughout the hospital stay. Furthermore, Perbet et al. (28) demonstrated that following $48 \mathrm{hrs}$ of inhalational sevoflurane sedation using the ACD, washout of sevoflurane was rapid. Marcos-Vidal et al. (29) similarly did not find any differences in creatinine levels in the serum of patients who were sedated after cardiac operations with sevoflurane or propofol. Similar results in relation to the effect of inhalation sedation on renal function have also been shown for isoflurane. (21)

Volatile anaesthetics cause a widening of the brain blood vessels, which in turn increases cerebral blood volume and intracranial pressure (ICP). Bösel et al. (30) analysed the effects of isoflurane on cerebral parameters in neuromonitored ICU stroke patients and showed that it is possible to reach sufficient sedation levels in cerebrovascular ICU patients by applying isoflurane long-term (mean 3.5 days), without a corresponding increase in ICP, if baseline values of ICP are low to moderately elevated. Although ICP values were increased by $2.1 \mathrm{mmHg}$ in the first hour after the transition of patients from an intravenous (with midazolam or propofol) to an inhalation form of sedation, these remained stable during the period of observation. However, after transition to inhalation sedation, a fall in mean arterial pressure and, consequently, cerebral perfusion pressure, was observed in patients, which required the additional use of vasopressors. They therefore propose the mandatory use of extended neuromonitoring of cerebrovascular ICU patients when sedated with volatile anaesthetics. Furthermore, Villa et al. (31) found that isoflurane increases regional cerebral blood flow in comparison to propofol in patients with severe subarachnoid haemorrhage, but the ICP 
values did not change significantly between the two forms of sedation. The study only included patients $(\mathrm{n}=13)$ with normal $(<18 \mathrm{mmHg})$ and untreated ICP.

Some studies $(29,32,33)$ have assessed whether the administration of volatile anaesthetics during the post-operative period has beneficial effects on markers of myocardial injury. Steurer et al. (32) found significantly lower values of serum troponin $\mathrm{T}$ in a group of patients sedated with sevoflurane ( $2 \mathrm{hrs}$ ) than in a propofol group. Studies by Marcos-Vidal et al. (29) and Hellström et al. (33) also confirmed that late postconditioning with sevoflurane might mediate cardiac protection.

Case reports on the use of the ACD in paediatric ICU are also worth mentioning. Jung et al. (34) reported the use of sevoflurane with the ACD for the sedation of a 30-month old girl with extensive burns. Sackey et al. (35) described long-term sedation with isoflurane with three children in paediatric ICU. In order to minimize the dead space of the $\mathrm{ACD}(100 \mathrm{~mL})$ and avoid high end-tidal $\mathrm{CO}_{2}$ concentrations in children (weighing less than $30 \mathrm{~kg}$ ), they inserted the ACD in the inspiratory limb of the breathing circuit. Recirculation of the anaesthetic gas is deliberately avoided, in a manner requiring a higher infusion rate in order to maintain the desired concentration of anaesthetic vapour.

The economic aspect of the use of inhalation sedation with the ACD is also important. Sackey et al. (36) demonstrated a $75 \%$ lower consumption of volatile anaesthetic with the ACD using high-flow ventilators in comparison with sedation via standard vaporizers. Two studies $(24,26)$ compared the costs of intravenous and inhalation sedation using the ACD. L'her et al. (26) found that inhalation sedation with isoflurane was less expensive (midazolam: $218 \pm 111$ EUR; isoflurane: $110 \pm 19 \mathrm{EUR}$ ) than average with patients who needed higher doses of midazolam for achieving a suitable depth of sedation. However, Röhm et al. (24) stated higher daily costs of sedation (including devicerelated equipment) in the case of inhalation sedation (sevoflurane: 65.49 \pm 10.52 EUR; propofol: $13.38 \pm 5.91$ EUR per patient). However, no study has been based on an exact economic analysis and taken into 
account the indirect costs of treatment in ICU, since Röhm et al. $(24,25)$ showed that patients sedated with volatile anaesthetics have a shorter ICU and hospital stay.

\section{Technical aspects of inhalation sedation with the ACD}

Some studies have focused on the technical aspects of the ACD, such as the effect of ventilation parameters on ACD performance, the influence of its internal volume (volume of the dead space) on the patient 's mechanical ventilation and the level of ambient pollution with volatile anaesthetics when using the ACD.

Belda et al. (37) demonstrated a high precision of the ACD in maintaining target concentrations of volatile anaesthetic (1.0 vol\% and 1.5 vol\%) in ICU patients, with the use of a simplified pharmacokinetic model for manually adjusted infusion of liquid sevoflurane. Berton et al. (38) highlighted that ventilation settings (respiratory rate and especially tidal volume) influence the vapour output of the ACD. The expired volatile anaesthetic fraction decreased when the tidal volume increased at a constant infusion flow rate of anaesthetic agent. The influence of respiratory minute volume on the performance of the ACD was also confirmed by Meiser et al. (20) They found that the ACD is accurate in maintaining target values of volatile anaesthetics as long as its reflecting capacity is not exceeded (10 mL of anaesthetic vapour contained in one expired breath; e.g., 1 vol\% in $1000 \mathrm{~mL}$ or 2 vol\% in $500 \mathrm{~mL}$, etc.). An increased minute ventilation therefore necessitates an increased infusion rate in order to keep the desired concentration of volatile anaesthetic in the breathing circuit.

Elevated arterial $\mathrm{CO}_{2}$ tension $\left(\mathrm{PaCO}_{2}\right)$ has been observed in patients when using the ACD, despite tidal volume compensation. $(24,27)$ The $\mathrm{ACD}$ has an internal volume of approximately $100 \mathrm{~mL}$, which additionally increases the anatomical dead space in a ventilated patient. Sturesson et al. (39) argue that use of the ACD increases the apparent dead space to a greater extent than can be explained by its internal 
volume. In fact, they demonstrated that the ACD adsorbs exhaled $\mathrm{CO}_{2}$, which is returned during the next inhalation cycle, creating an additional apparent dead space. In further studies, the same authors found that the humidity of the gas exhaled by the patient (40) and the presence of volatile anaesthetic in the breathing circuit (41) reduce the rebreathing of $\mathrm{CO}_{2}$, although it is still present. A study on patients sedated with sevoflurane using the ACD showed an $88 \mathrm{~mL}$ larger apparent dead space than with a conventional heat and moisture exchanger $(50 \mathrm{~mL}$ due to the larger internal volume of the ACD and $38 \mathrm{~mL}$ due to the rebreathing of $\mathrm{CO}_{2}$ ). (41) A larger apparent dead space could be significant in patients with pathological states connected with inefficient oxygen and $\mathrm{CO}_{2}$ exchange, such as patients with acute respiratory distress syndrome (ARDS), since lung protective ventilation with low tidal volumes is recommended for them. $(27,40)$ Calculations by Sturesson et al. (41) showed that with use of the ACD, it may be difficult to maintain normocapnia in patients with tidal volume $<6 \mathrm{~mL} / \mathrm{kg}$, even when the respiratory rate is increased. A recent study by Chabanne et al. (42) showed that use of the ACD in ICU patients worsens ventilatory parameters, with significant increases in the work of breathing, minute ventilation, intrinsic positive end-expiratory pressure and inspiratory pressure swings. Sevoflurane use via the ACD (for a light-sedation target) normalizes respiratory parameters, so it might be an alternative method for sedation in ICU patients, at least during the weaning process with pressure-support ventilation.

Various studies have ascertained environmental pollution with volatile anaesthetics using the $\mathrm{ACD}$, since central gas scavenging systems are rare in ICU. (18) In the European Union, the upper exposure limit for isoflurane in the workplace is $50 \mathrm{ppm}$ per hour. (43) Studies in ICU have shown that, with the use of scavenging systems (either active or passive), values of volatile anaesthetics remain below the aforementioned permitted limit when they are administered with the ACD. $(18,26,36)$ Some studies $(36,44)$ have also shown that adequate room air exchanges per hour without using any form of gas scavenging maintains 
environmental pollution within permitted limits. Djafari Marbini et al. (44) measured the ambient levels of isoflurane $<2 \mathrm{ppm}$ in the vicinity of a patient's head and the predicted nursing area with ten room air exchanges per hour. Stackey et al. (36) looked at ambient isoflurane pollution utilizing active scavenging and four room air exchanges per hour, in 15 patients during ICU sedation for $12-96 \mathrm{hrs}$. Five patients in this study had no active scavenging and relied on room air exchanges alone. The mean levels of isoflurane pollution were $<0.5 \mathrm{ppm}$ in all patients. Despite the fact that studies show low environmental pollution with volatile anaesthetics using the ACD, these are based on small samples and a low number of measurements. Similarly, the conditions under which pollution with gas anaesthetics was measured were various. This aspect of the use of the ACD must therefore be additionally studied.

\section{Discussion}

The clinical use of inhalation sedation in ICU was described in the late 1980s for patients with bronchial asthma and patients with drug abuse or addiction syndromes, since in such cases a combination of a variety of hypnotics and analgesics are required for adequate analgosedation. (19) With the arrival of the ACD on the market, inhalation sedation in ICU has been increasingly established in various countries of the European Union and Canada. $(18,20,22,23)$ Research to date has shown that the use of inhalation sedation with the ACD in ICU is simple and safe for both patients and staff. $(26,27,37)$

The literature included in the review shows that use of inhalation sedation enables faster transition to spontaneous breathing and removal of the ET-tube and a shorter awakening time of patients than with intravenous sedation. (21-23) In addition, patients sedated with volatile anaesthetics need less analgesics $(22,26)$ and the hospital stay is shorter. $(24,25)$ Even short-term inhalation sedation of patients after cardiac operations has a cardioprotective effect and reduces values of troponin $\mathrm{T}$. $(29,32)$ Similarly, inhalation sedation using the ACD enables direct control of the concentration of volatile anaesthetic in the breathing 
circuit, so the depth of sedation of a patient can be easily monitored and titrated. $(21,33)$

Jackson et al. (45) reported that $33 \%$ to $57 \%$ of patients in ICU do not receive appropriate drugs and doses that enable suitable analgesia and depth of sedation. Too-deep sedation and analgesia prolongs the need for mechanical ventilation and increases the risk of occurrence of pneumonia and sepsis, (46) increases the risk of haemodynamic instability, which can prolong the ICU stay and increase the mortality of patients. (1) Too-shallow sedation and analgesia can cause fear, pain, stress and anxiety, which increase the level of endogenous catecholamines, increase the metabolism and use of oxygen, arterial pressure and incidence of tachyarrhythmia, which can cause additional complications in the treatment of a critically ill patient. (47)

Although only a minor percentage of isoflurane and sevoflurane is metabolised by the kidneys because of the formation of fluoride ions, concerns about their nephrotoxicity are still present. Plasma fluoride concentrations exceeding $50 \mu \mathrm{mol} / \mathrm{L}$ and the risk of kidney injury have been described with methoxyflurane. (48) Several studies have found elevated values of inorganic fluoride more than 50 or $100 \mu \mathrm{mol} / \mathrm{L}$. $(22,25,28)$ However, despite increased concentrations of inorganic fluoride in serum after sevoflurane exposure, glomerular and tubular renal integrity were preserved in patients $(22,25)$ even after long-term sedation with sevoflurane. (28) Two factors may explain these differences between methoxyflurane and sevoflurane: a) it is not the peak serum fluoride concentration but the duration of the systemic fluoride that is important. Sevoflurane is less soluble than methoxyflurane in blood and tissues; sevoflurane thus exits the body much more rapidly; and b) the liver is the primary organ of metabolism of sevoflurane, whereas both the liver and kidney metabolize methoxyflurane. (49) The high local (intrarenal) production of fluoride ions from methoxyflurane probably explains the greater capacity of that anaesthetic to produce renal injury from fluoride production. This is in agreement with several studies in which no differences in creatinine levels in the serum of patients who were sedated with sevoflurane, propofol or isoflurane were 
reported. $(21,29)$

Despite the large number of studies investigating the use of inhalation sedation with the ACD in adult patients, almost no research has been carried out on the use of inhalation sedation in critically ill children. It is well known that optimal sedation in critically ill children is often difficult to achieve due to the altered pharmacokinetics and dynamics in children. Tolerance and withdrawal after long-term benzodiazepine use in paediatric ICU has been described. (50) Furthermore, some studies have shown the clinical usefulness of volatile anaesthetics for sedation in children. $(51,52)$ To date, only a few case reports have described inhalation sedation with ACD in paediatric ICU with encouraging results $(34,35)$, and further evaluation of the usefulness of this method of sedation for paediatric patients is still needed.

In adult patients without pulmonary pathology, the additional dead space of the ACD can be considered clinically unimportant, although some studies have identified increased values of $\mathrm{PaCO}_{2}$ in patients. $(24,27)$ Values of $\mathrm{PaCO}_{2}$ were therefore balanced with higher tidal volumes and/or respiratory rates. Sturesson et al. (41) demonstrated that, with the use of the ACD, normocapnia may be difficult to maintain when using a low tidal volume, even when the respiratory rate is increased. This might limit the usefulness of ACD in clinical settings. In fact, lung protective ventilation (mechanical ventilation with low respiratory volumes, $\leq 6 \mathrm{~mL} / \mathrm{kg}$ ), is of key importance and an integral part of treatment of patients with ARDS. (53) However, hypercapnia is a central component of current protective ventilatory strategies. Increasing clinical evidence supports the use of permissive hypercapnia, particularly in acute lung injury/ARDS, status asthmaticus, chronic obstructive pulmonary disease and neonatal respiratory failure, in order to avoid the deleterious effects of high lung stretch. (54) Additionally, with inhalational sedation, spontaneous breathing can be maintained and, if necessary, may be augmented by various ventilator modes. $(8,42)$ Although some authors $(27,41)$ argue that the use of the ACD might not be appropriate for patients with respiratory diseases with increased 
physiological dead space and/or ventilation difficulties, there are still no clear guidelines or research in this field. According to the manufacturer's instructions, the use of the ACD is advised only in patients with a tidal volume $>350 \mathrm{~mL}$. (8)

\section{Conclusion}

Because of their pharmacokinetic properties, use of volatile anaesthetics with ICU patients is becoming increasingly interesting, especially for some groups of critically ill patients. With the arrival of the ACD, their use in ICU has finally become available. However, the number of prospective randomised clinical studies investigating the effectiveness and safety of inhalation sedation of ICU patients using the ACD is relatively small. We also highlighted some issues that are still unclear (the influence of the ACD dead space on patient ventilation, gas scavenging, the cost of inhalation sedation with ACD etc.) and need to be additionally explored. Otherwise, the results to date show that inhalation sedation with the ACD can be a useful alternative to existing protocols of intravenous sedation of patients requiring intensive treatment.

\section{References}

1. Jacobi J, Fraser GL, Coursin DB, Riker RR, Fontaine D, Wittbrodt ET, et al. Clinical practice guidelines for the sustained use of sedatives and analgesics in the critically ill adult. Crit Care Med 2002;30(1):119-41.

2. Sessler CN, Varney K. Patient-focused sedation and analgesia in the ICU. Chest 2008;133(2):552-65.

3. Barr J, Fraser GL, Puntillo K, Ely EW, Gélinas C, Dasta JF, et al. Clinical practice guidelines for the management of pain, agitation, and delirium in adult patients in the intensive care unit. Crit Care Med 2013;41(1):263306.

4. Vasile B, Rasulo F, Candiani A, Latronico N. The pathophysiology of propofol infusion syndrome: a simple name for a complex syndrome. Intensive Care Med 2003;29(9):1417-25. 
5. Shafer A. Complications of sedation with midazolam in the intensive care unit and a comparison with other sedative regimens. Crit Care Med 1998;26(5):947-56.

6. Sakai EM, Connolly LA, Klauck JA. Inhalation anesthesiology and volatile liquid anesthetics: focus on isoflurane, desflurane, and sevoflurane. Pharmacotherapy 2005;25(12):1773-88.

7. Sturesson LW, Johansson A, Bodelsson M, Malmkvist G. Wash-in kinetics for sevoflurane using a disposable delivery system (AnaConDa) in cardiac surgery patients. Br J Anaesth 2009;102(4):470-6.

8. Meiser A, Laubenthal H. Inhalational anaesthetics in the ICU: theory and practice of inhalational sedation in the ICU, economics, risk-benefit. Best Pract Res Clin Anaesthesiol 2005;19(3):523-38.

9. Shiraishi Y, Ikeda K. Uptake and biotransformation of sevoflurane in humans: a comparative study of sevoflurane with halothane, enflurane, and isoflurane. J Clin Anesth 1990;2(6):381-6.

10. Hornuss C, Firsching M, Dolch M, Martignoni A, Peraud A, Briegel J. Long-term isoflurane therapy for refractory bronchospasm associated with herpes simplex pneumonia in a heart transplant patient. Case Rep Med 2010;2010:746263.

11. Tanigami H, Yahagi N, Kumon K, Watanabe Y, Haruna M, Matsui J, et al. Long-term sedation with isoflurane in postoperative intensive care in cardiac surgery. Artif Organs 1997;21(1):21-3.

12. Kehl F, Payne RS, Roewer N, Schurr A. Sevoflurane-induced preconditioning of rat brain in vitro and the role of KATP channels. Brain Res 2004;1021(1):76-81.

13. Thomasson R, Luttropp HH, Werner O. A reflection filter for isoflurane and other anaesthetic vapours. Eur J Anaesthesiol 1989;6(2):89-94.

14. Feigin DS. Misconceptions regarding the pathogenicity of silicas and silicates. J Thorac Imaging 1989;4(1):68-80.

15. Dahm SL, Steptoe P, Luttropp HH, Reinstrup P. Charcoal as an airway isoflurane reflection filter. Eur J Anaesthesiol 1998;15(2):230-3.

16. Misra S, Koshy T. A review of the practice of sedation with inhalational anaesthetics in the intensive care unit with the AnaConDa $\AA$ device. Indian J Anaesth 2012;56(6):518-23.

17. Enlund M, Wiklund L, Lambert H. A new device to reduce the 
consumption of a halogenated anaesthetic agent. Anaesthesia 2001;56(5):429-32.

18. Pickworth T, Jerath A, DeVine R, Kherani N, Wąsowicz M. The scavenging of volatile anesthetic agents in the cardiovascular intensive care unit environment: a technical report. Can J Anaesth 2013;60(1):3843.

19. Soukup J, Schärff K, Kubosch K, Pohl C, Bomplitz M, Kompardt J. State of the art: sedation concepts with volatile anesthetics in critically Ill patients. J Crit Care 2009;24(4):535-44.

20. Meiser A, Bellgardt M, Belda J, Röhm K, Laubenthal H, Sirtl C. Technical performance and reflection capacity of the anaesthetic conserving device-a bench study with isoflurane and sevoflurane. J Clin Monit Comput 2009;23(1):11-9.

21. Sackey PV, Martling CR, Granath F, Radell PJ. Prolonged isoflurane sedation of intensive care unit patients with the Anesthetic Conserving Device. Crit Care Med 2004;32(11):2241-6.

22. Mesnil M, Capdevila X, Bringuier S, Trine PO, Falquet Y, Charbit J, et al. Long-term sedation in intensive care unit: a randomized comparison between inhaled sevoflurane and intravenous propofol or midazolam. Intensive Care Med 2011;37(6):933-41.

23. Hellström J, Öwall A, Sackey PV. Wake-up times following sedation with sevoflurane versus propofol after cardiac surgery. Scand Cardiovasc $\mathrm{J}$ 2012;46(5):262-8.

24. Röhm KD, Wolf MW, Schöllhorn T, Schellhaass A, Boldt J, Piper SN. Short-term sevoflurane sedation using the Anaesthetic Conserving Device after cardiothoracic surgery. Intensive Care Med 2008;34(9):1683-9.

25. Röhm KD, Mengistu A, Boldt J, Mayer J, Beck G, Piper SN. Renal integrity in sevoflurane sedation in the intensive care unit with the anesthetic-conserving device: a comparison with intravenous propofol sedation. Anesth Analg 2009;108(6):1848-54.

26. L'her E, Dy L, Pili R, Prat G, Tonnelier JM, Lefevre M, et al. Feasibility and potential cost/benefit of routine isoflurane sedation using an anesthetic-conserving device: a prospective observational study. Respir Care 2008;53(10):1295-303. 
27. Migliari M, Bellani G, Rona R, Isgrò $S$, Vergnano $B$, Mauri T, et al. Shortterm evaluation of sedation with sevoflurane administered by the anesthetic conserving device in critically ill patients. Intensive Care Med 2009;35(7):1240-6.

28. Perbet S, Bourdeaux D, Sautou V, Pereira B, Chabanne R, Constantin $\mathrm{JM}$, et al. A pharmacokinetic study of 48-hour sevoflurane inhalation using a disposable delivery system (AnaConDa $($ ) in ICU patients. Minerva Anestesiol 2014;80(6):655-65.

29. Marcos-Vidal JM, González R, Garcia C, Soria C, Galiana M, De Prada B. Sedation with sevoflurane in postoperative cardiac surgery: influence on troponin $T$ and creatinine values. Heart Lung Vessel 2014;6(1):33-42.

30. Bösel J, Purrucker JC, Nowak F, Renzland J, Schiller P, Pérez EB, et al. Volatile isoflurane sedation in cerebrovascular intensive care patients using AnaConDa(®): effects on cerebral oxygenation, circulation, and pressure. Intensive Care Med 2012;38(12):1955-64.

31. Villa F, Iacca C, Molinari AF, Giussani C, Aletti G, Pesenti A, et al. Inhalation versus endovenous sedation in subarachnoid hemorrhage patients: effects on regional cerebral blood flow. Crit Care Med 2012;40(10):2797-804.

32. Steurer MP, Steurer MA, Baulig W, Piegeler T, Schläpfer M, Spahn DR, et al. Late pharmacologic conditioning with volatile anesthetics after cardiac surgery. Crit Care 2012;16(5):R191.

33. Hellström J, Öwall A, Bergström J, Sackey PV. Cardiac outcome after sevoflurane versus propofol sedation following coronary bypass surgery: a pilot study. Acta Anaesthesiol Scand 2011;55(4):460-7.

34. Jung C, Granados M, Marsol P, Murat I, Gall O. Use of sevoflurane sedation by the AnaConDa device as an adjunct to extubation in a pediatric burn patient. Burns 2008;34(1):136-8.

35. Sackey PV, Martling CR, Radell PJ. Three cases of PICU sedation with isoflurane delivered by the »AnaConDa«. Paediatr Anaesth 2005;15(10):879-85.

36. Sackey PV, Martling CR, Nise G, Radell PJ. Ambient isoflurane pollution and isoflurane consumption during intensive care unit sedation with the Anesthetic Conserving Device. Crit Care Med 2005;33(3):585-90.

37. Belda JF, Soro M, Badenes R, Meiser A, García ML, Aguilar G, et al. The 
predictive performance of a pharmacokinetic model for manually adjusted infusion of liquid sevofluorane for use with the AnestheticConserving Device (AnaConDa): a clinical study. Anesth Analg 2008;106(4):1207-14.

38. Berton J, Sargentini C, Nguyen JL, Belii A, Beydon L. AnaConDa reflection filter: bench and patient evaluation of safety and volatile anesthetic conservation. Anesth Analg 2007;104(1):130-4.

39. Sturesson LW, Malmkvist G, Bodelsson M, Niklason L, Jonson B. Carbon dioxide rebreathing with the anaesthetic conserving device, AnaConDa®. Br J Anaesth 2012;109(2):279-83.

40. Sturesson LW, Bodelsson M, Johansson A, Jonson B, Malmkvist G. Apparent dead space with the anesthetic conserving device, AnaConDa $®$ : a clinical and laboratory investigation. Anesth Analg 2013;117(6):1319-24.

41. Sturesson LW, Bodelsson M, Jonson B, Malmkvist G. Anaesthetic conserving device AnaConDa ${ }^{\circledR}$ : dead space effect and significance for lung protective ventilation. Br J Anaesth 2014;113(3):508-14.

42. Chabanne R, Perbet S, Futier E, Ben Said NA, Jaber S, Bazin JE, et al. Impact of the anesthetic conserving device on respiratory parameters and work of breathing in critically ill patients under light sedation with sevoflurane. Anesthesiology 2014;121(4):808-16.

43. European Agency for Safety and Health at Work. Directive 2009/161/EU - indicative occupational exposure limit values. [cited 2015 July 19]. Available from: URL: https://osha.europa.eu/en/legislation/directives/commission-directive2009-161-eu-indicative-occupational-exposure-limit-values.

44. Djafari Marbini H, Palayiwa E, Chantler J. Active gas scavenging is unnecessary when using the AnaConDa volatile agent delivery system. JICS 2009;10:26-8.

45. Jackson DL, Proudfoot CW, Cann KF, Walsh TS. The incidence of suboptimal sedation in the ICU: a systematic review. Crit Care 2009;13(6):R204.

46. Chanques G, Jaber S, Barbotte E, Violet S, Sebbane M, Perrigault PF, et al. Impact of systematic evaluation of pain and agitation in an intensive care unit. Crit Care Med 2006;34(6):1691-9. 
47. Bourne RS, Mills GH. Sleep disruption in critically ill patientspharmacological considerations. Anaesthesia 2004;59(4): 374-84.

48. Taves DR, Fry BW, Freeman RB, Gillies AJ. Toxicity following methoxyflurane anesthesia. II. Fluoride concentrations in nephrotoxicity. JAMA 1970;214(1):91-5.

49. Kharasch ED, Hankins DC, Thummel KE. Human kidney methoxyflurane and sevoflurane metabolism. Intrarenal fluoride production as a possible mechanism of methoxyflurane nephrotoxicity. Anesthesiology 1995;82(3):689-99.

50. Tobias JD. Tolerance, withdrawal, and physical dependency after longterm sedation and analgesia of children in the pediatric intensive care unit. Crit Care Med 2000;28(6):2122-32.

51. Curley MA, Molengraft JA. Providing comfort to critically ill pediatric patients: isoflurane. Crit Care Nurs Clin North Am 1995;7(2):267-74.

52. Wheeler DS, Clapp CR, Ponaman ML, Bsn HM, Poss WB. Isoflurane therapy for status asthmaticus in children: A case series and protocol. Pediatr Crit Care Med 2000;1(1):55-9.

53. Ventilation with lower tidal volumes as compared with traditional tidal volumes for acute lung injury and the acute respiratory distress syndrome. The Acute Respiratory Distress Syndrome Network. N Engl J Med 2000;342(18):1301-8.

54. Ni Chonghaile M, Higgins B, Laffey JG. Permissive hypercapnia: role in protective lung ventilatory strategies. Curr Opin Crit Care 2005;11(1):5662. 


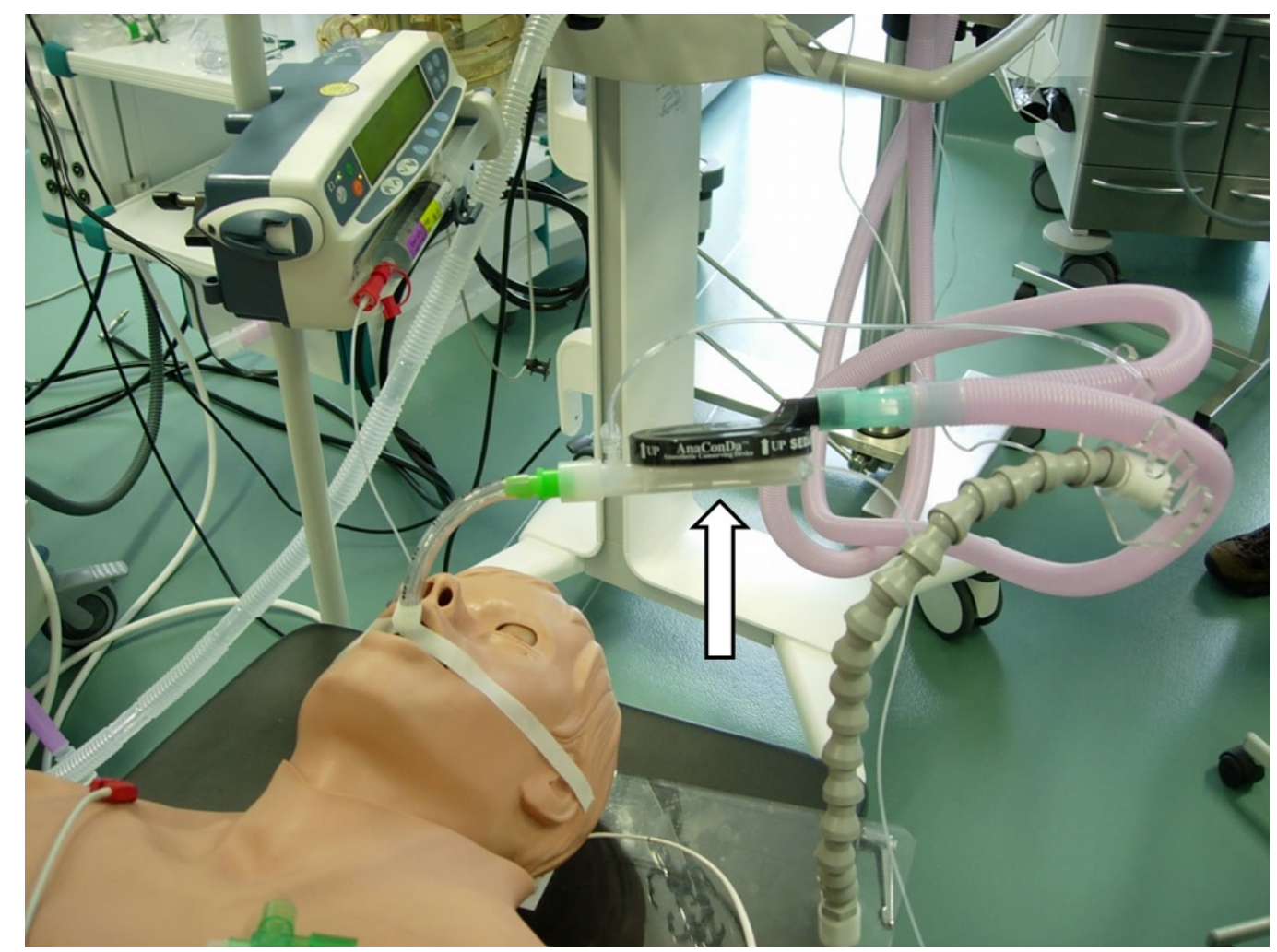

Figure 1. Connection of the AnaConDa (arrow) to the ventilator circuit on high-fidelity simulator.

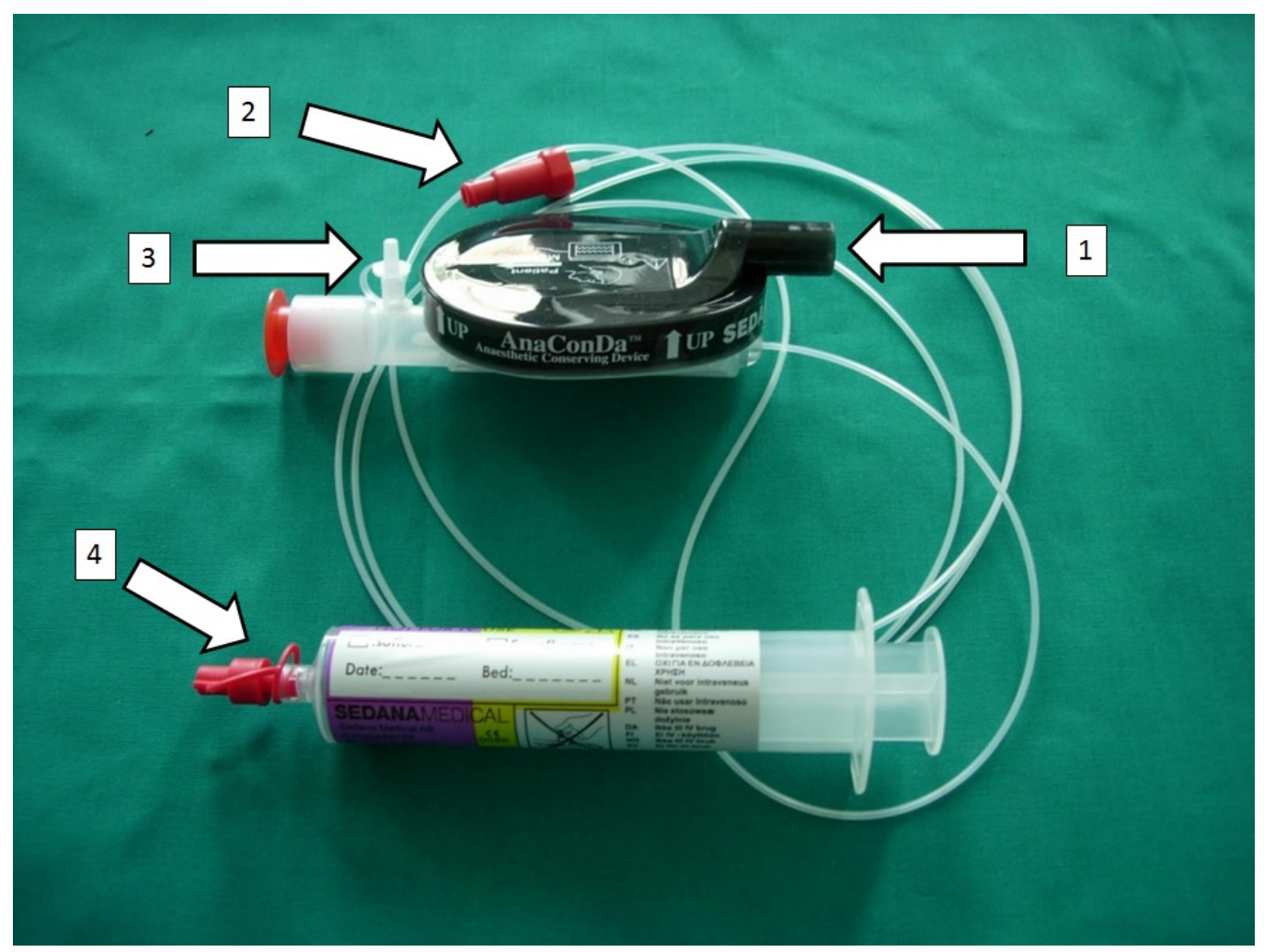

Figure 2. AnaConDa system components: 1 AnaConDa device, 2 Agent 
supply line with valve and screw cap, 3 Gas measurement port, 4

AnaConDa syringe with screw coupling and screw cap.

Table 1. Randomised clinical studies of inhalation sedation using the ACD in ICU patients.

\section{Number of patients Authors/year (n) and cause of sedation in ICU}

$$
\mathrm{n}=40
$$

heterogeneous

pathology

Sackey et al., (respiratory 2004 (21)

failure, respiratory obstruction, sepsis, trauma etc.)

Established advantages Comparable Duration of anaesthetics ${ }_{\text {sedation }}$ inhalation sedation with ACD

- time of awakening significantly shorter (faster $\mathrm{I} / \mathrm{M}$ Sedation removal of $>12$ hrs ET-tube, faster capacity to follow verbal instructions)

- excellent precision of $\begin{array}{lll} & \mathrm{n}=50 ; & \\ \text { Belda et al., } & \text { patients } & \text { S target } \\ \text { after major } & \text { conc. 1.o } \\ \text { vol\% (37) } & \begin{array}{l}\text { surgical } \\ \text { operations }\end{array} & \mathbf{1 . 5 \text { vol\% }}\end{array}$

$\mathrm{n}=70$ patients after

Röhm et al., 2008 (24) cardiothoracic operations (coronary artery
$\mathrm{S} / \mathrm{P}$

$6 \mathrm{hrs}$

after operation
ACD in delivering volatile anaesthetic within 6 hours

- shorter recovery after sedation(faster removal of ET-tube, Short- faster term capacity to sedation follow (<12 verbal hrs) instructions) 


\begin{tabular}{|c|c|c|c|c|}
\hline $\begin{array}{l}\text { Röhm et al., } \\
2009 \text { (25) }\end{array}$ & $\begin{array}{l}\mathrm{n}=125 ; \\
\text { patients } \\
\text { after major } \\
\text { abdominal, } \\
\text { vascular } \\
\text { and thoracic } \\
\text { operations }\end{array}$ & $\mathrm{S} / \mathrm{P}$ & $\begin{array}{l}\text { Sedation } \\
\text { up to } \\
24 \mathrm{hrs}\end{array}$ & $\begin{array}{l}\text { - shorter } \\
\text { mechanical } \\
\text { ventilation } \\
\text { of patients } \\
\text { - shorter } \\
\text { time of } \\
\text { hospital } \\
\text { stay } \\
\text { - despite } \\
\text { increased } \\
\text { values of } \\
\text { inorganic } \\
\text { fluorides, } \\
\text { renal } \\
\text { function } \\
\text { was } \\
\text { preserved } \\
\text { during the } \\
\text { time of } \\
\text { treatment }\end{array}$ \\
\hline $\begin{array}{l}\text { Mesnil et al., } \\
2011 \text { (22) }\end{array}$ & $\begin{array}{l}\mathrm{n}=60 ; \\
\text { heterogeneous } \\
\text { pathology } \\
\text { (trauma, } \\
\text { pneumonia, } \\
\text { sepsis, acute } \\
\text { respiratory } \\
\text { failure etc.) }\end{array}$ & $\mathrm{S} / \mathrm{P}$ and $\mathrm{M}$ & $\begin{array}{l}\text { Sedation } \\
>24 \mathrm{hrs} \\
\text { (or < } \\
96 \mathrm{hrs})\end{array}$ & $\begin{array}{l}\text { - shorter } \\
\text { time of } \\
\text { wakening } \\
\text { and faster } \\
\text { removal of } \\
\text { the ET-tube } \\
\text { - lower use } \\
\text { of } \\
\text { analgesics } \\
\text { (in } 24 \text { hrs } \\
\text { after } \\
\text { extubation) } \\
\text { - fewer } \\
\text { post- } \\
\text { sedation } \\
\text { hallucinatio }\end{array}$ \\
\hline
\end{tabular}


n episodes

\begin{tabular}{|c|c|c|c|c|}
\hline $\begin{array}{l}\text { Hellström et } \\
\text { al., } 2011 \text { (33) }\end{array}$ & $\begin{array}{l}\mathrm{n}=100 ; \\
\text { patients } \\
\text { after } \\
\text { coronary } \\
\text { artery } \\
\text { bypass graft } \\
\text { surgery }\end{array}$ & $\mathrm{S} / \mathrm{P}$ & $\begin{array}{l}\text { Min } 2 \\
\text { hours }\end{array}$ & $\begin{array}{l}\text { - post hoc } \\
\text { analysis } \\
\text { showed } \\
\text { significantly } \\
\text { lower } \\
\text { values of } \\
\text { cTnT for the } \\
\text { period of } 12 \\
\text { hours after } \\
\text { the } \\
\text { operation }\end{array}$ \\
\hline $\begin{array}{l}\text { Hellström et } \\
\text { al., } 2012 \\
(23)\end{array}$ & $\begin{array}{l}\mathrm{n}=100 ; \\
\text { patients } \\
\text { after } \\
\text { coronary } \\
\text { artery } \\
\text { bypass graft } \\
\text { surgery }\end{array}$ & $\mathrm{S} / \mathrm{P}$ & $\begin{array}{l}\text { Min } 2 \\
\text { hours }\end{array}$ & $\begin{array}{l}\text { - faster } \\
\text { removal of } \\
\text { ET-tube } \\
\text { - faster } \\
\text { verbal } \\
\text { response of } \\
\text { patient }\end{array}$ \\
\hline $\begin{array}{l}\text { Steurer et } \\
\text { al., } 2012 \\
(32)\end{array}$ & $\begin{array}{l}\mathrm{n}=117 ; \\
\text { patients } \\
\text { after heart } \\
\text { surgery }\end{array}$ & $\mathrm{S} / \mathrm{P}$ & $\begin{array}{l}\text { Sedation } \geq \\
4 \text { hours }\end{array}$ & $\begin{array}{l}\text { - troponin } \\
\text { T values } \\
\text { significantly } \\
\text { lower on } \\
\text { the first day } \\
\text { after } \\
\text { operation }\end{array}$ \\
\hline $\begin{array}{l}\text { Marcos- } \\
\text { Vidal et al., } \\
2014 \text { (29) }\end{array}$ & $\begin{array}{l}\mathrm{n}=126 ; \\
\text { patients } \\
\text { after heart } \\
\text { surgery }\end{array}$ & $\mathrm{S} / \mathrm{P}$ & $\begin{array}{l}\text { Min } 3 \\
\text { hours }\end{array}$ & $\begin{array}{l}\text { - troponin } \\
\text { T values } \\
\text { significantly } \\
\text { lower } 12 \\
\text { and } 48 \\
\text { hours after } \\
\text { surgery } \\
\text { - no } \\
\text { differences } \\
\text { between } \\
\text { groups in } \\
\text { creatinine } \\
\text { levels } \\
\text { before }\end{array}$ \\
\hline
\end{tabular}


ACD, AnaConDa; ET-tube, endotracheal tube; I, isoflurane; ICU, intensive care unit; M, midazolam; min, minimum; P, propofol; S, sevoflurane.

Karnjuš I

Department of Nursing, Faculty of Health Sciences, University of Primorska, Izola, Slovenia

Mekiš D

Department of Anaesthesiology, Intensive Care and Pain Management, University Medical Centre Maribor, Maribor, Slovenia

Mekiš D, Križmarić M

Department of Anaesthesiology and Reanimation, Faculty of Medicine, University of Maribor, Maribor, Slovenia

Correspondence to:

Igor Karnjuš

Department of Nursing

Faculty of Health Sciences, University of Primorska

Polje 42, 6310 Izola, Slovenia

Phone: +3865662 6478

Fax: + 38656626480

E-mail: igor.kanjus@fvz.upr.si

Article printed from Signa Vitae: http://www.signavitae.com URL to article: http://www.signavitae.com/2016/o5/inhalationsedation-with-the-anaesthetic-conserving-device-for-patientsin-intensive-care-units-a-literature-review/

Copyright (C) 2015 Signa Vitae. All rights reserved. 